\title{
RANCANG BANGUN CONVEYOR AUTO ELECTROPLATING BERBASIS ARDUINO MEGA
}

\author{
Baqu Sari ${ }^{1}$, Much Sobri Sungkar ${ }^{2}$, Rony Darpono ${ }^{3}$ \\ 12 Teknik Elektronika Politeknik Harapan Bersama Tegal (9 pt) \\ email: ${ }^{1}$ baqusari@gmail.com, ${ }^{2}$ sobrisungkar@gmail.com, ${ }^{3}$ ronydr80@gmail.com
}

\begin{abstract}
Dunia industri saat ini memerlukan suatu peralatan yang dapat bekerja secara otomatis untuk meningkatkan produktivitas, mempersingkat waktu produksi, menurunkan biaya produksi dan meniadakan pekerjaan-pekerjaan rutin dan membosankan yang harus dilakukan manusia. Perkembangan teknologi saat ini sangatlah pesat, dari mulai hal sepele hingga yang membutuhkan tingkat ketelitian yang tinggi.

Metode yang digunakan adalah waterfall adalah model SDLC (system development life cycle) konvensional, linier dan berurutan yang dimulai dari perencanaan, analisis kebutuhan, desain, implementasi, pengujian dan perawatan.

Hasil dari pengujian yang dilakukan adalah alat dapat merespon perintah dengan tepat dan berjalan sesuai yang diperintahkan. Penggunaan limith switch sebagai sensor input dapat memberikan perintah secara akurat. Penggunaan mode manual dan otomatis dengan perangkat smartphone dapat mempermudah dan meringankan pekerjaan dan dengan adanya perangkat ini mahasiswa dapat mempelajari masing-masing komponen yang ada pada perangkat ini dengan mudah karena dihadapi dengan aplikasi komponen tersebut secara riil.
\end{abstract}

\section{Kata Kunci : Electroplating, Dunia Industri}

\section{PENDAHULUAN}

Dunia industri saat ini memerlukan suatu peralatan yang dapat bekerja secara otomatis untuk meningkatkan produktivitas, mempersingkat waktu produksi, menurunkan biaya produksi dan meniadakan pekerjaan-pekerjaan rutin dan membosankan yang harus dilakukan manusia[1]. Banyak alat yang digunakan untuk meringankan beban manusia dalam proses produksi dalam industri. Perkembangan teknologi saat ini sangatlah pesat, dari mulai hal sepele hingga yang membutuhkan tingkat ketelitian yang tinggi. Salah satu bukti perkembangan teknologi saat ini munculnya penemuan atau pembuatan robot yang menggunakan sistem otomasisasi yang dapat bekerja secara otomatis dan sesuai dengan apa yang diperintahkan sehingga manusia bertugas hanya sebagai operator dan robot yang mengerjakan produksi sebuah barang. Dengan adanya penemuan berupa robot maka dapat meringankan beban produksi suatu barang dan dapat mempercepat waktu produksi sekaligus memperkecil kemungkinan kecelakaan kerja.

Pengangkutan dari unit produksi satu ke yang lainnya dapat menggunakan alat konveyor, elevator dan lain-lain. Suatu proses pemindahan barang atau material merupakan proses yang memerlukan ketepatan dan ketelitian yang memerlukan alat bantu untuk mempermudah proses pengerjaan yaitu berupa konveyor yang berfungsi untuk menghantarkan barang atau material dari proses satu ke proses selanjutnya. Pada proses produksi sparepart logam dibutuhkan konveyor yang mampu menahan beban berat dengan tarikan yang kuat. Conveyor Chain atau konveyor rantai dapat mengangkat beban berat, misalnya palet, kotak grid, wadah industri dan juga biaya part yang relatif murah. Selain itu Konveyor rantai dapat kombinasi gerakan horizoltal dan vertikal, mengangkut dan memindahkan. Proses produksi sparepart logam membutuhkan ketelitian dan konsentrasi yang penuh agar dapat meminimalisir kecelakaan kerja dan hasil produksi yang tidak baik dikarenakan proses pembuatan sparepart logam berhubungan langsung dengan cairan kimia yang berbahaya untuk tubuh manusia, sehingga seringkali operator tidak fokus dengan keselamatan dirinya dan memepercepat proses produksi dan mengabaikan standar yang dibutuhkan dalam pembuatan sparepart logam sehingga saat adanya kecacatan dalam sparepart logam yang dibuat maka akan memperbesar biaya produksi maka perlunya sebuah alat yang dapat mengurangi berbagai kemungkinan kesalahan yang terjadi.

\section{Tinjauan Pustaka}

1.1. Electropalting

Lapis dengan listrik (electroplating) adalah suatu proses pengendapan zat atau ion-ion logam pada elektroda katoda (negatif) dengan cara elektrolis. Hasil dari elektrolis tersebut akan mengendap pada elektroda negatif/ katoda. Terjadinya suatu endapan pada proses ini disebabkan adanya ion-ion bermuatan listrik yang berpindah dari suatu elektroda melalui elektrolit. Endapan yang terjadi bersifat adhesif terhadap logam dasar.

\section{METODE PENELITIAN}

Dalam membuat suatu alat atau sistem menggunakan prosedur atau model penelitian dengan model waterfall adalah model SDLC (system development life cycle) konvensional, linier dan berurutan yang dimulai dari perencanaan, analisis kebutuhan, desain, implementasi, pengujian dan perawatan.

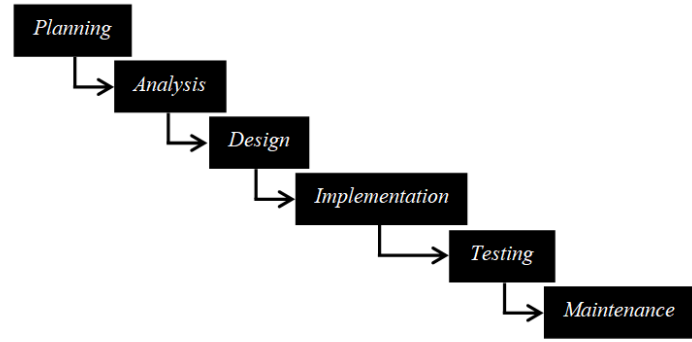

Gambar 3.1 Model Waterfall SLDC

Sesuai dengan model waterfall di atas, dalam membuat suatu alat atau sistem dimulai dari tahap perencanaan, lalu menuju analisis kebutuhan, kemudian menuju tahap desain, setelah itu menuju tahap implementasi lalu tahap pengujian dan terakhir tahap perbaikan, jika terdapat kesalahan maka akan diperbaiki..

\section{Hasil Penelitian dan Pembahasan} 4.4.1.Perancangan Skema Rangkaian

Perancangan skema rangkaian dibuat menggunakan aplikasi fritzing. Pembuatan skema sangat perlu dilakukan agar nantinya saat perakitan alat tidak salah rakit. Pada halaman berikutnya skema rangkaian Konveyor Auto Electroplating Berbasis Arduino Mega.

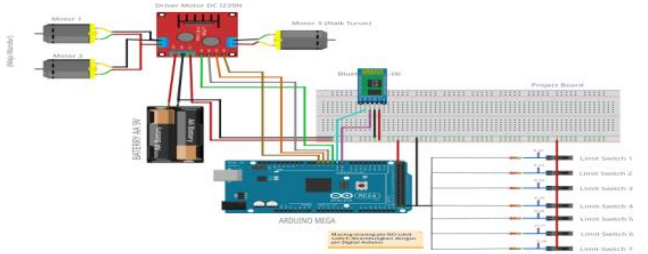


Gambar 4.1. Rancangan alat konveyor Auto Electroplating berbasis Arduino Mega

Penjelasan peran masing-masing komponen pada alat konveyor Auto Electroplating berbasis Arduino Mega diatas yaitu:

1. Arduino Mega sebagai pengatur otomatis on/off pada motoran.

2. Bluetooth HC-06 sebagai pengatur manual on/off pada motoran melalui jaringan nirkabel.

3. Driver L329D sebagai saklar sebelum menuju output/motoran

4. Limit Switch sebagai input/pemberi data keterangan on/off terhadap Arduino Mega untuk menjalankan program otomatis on/off motoran.

5. Motor DC sebagai penggerak dudukan pembawa motor $U P / D O W N$

6. Resistor sebagai pembatas tegangan pada input limith swicth.

7. Project Board sebagai terminal/dudukan untuk pin Arduino Mega ke semua komponen karena pin Arduino Mega hanya untuk satu kabel jumper. Sedangkan untuk pin power banyak digunakan.

Gambar alat secara real dan nama komponennya adalah sebagai berikut :

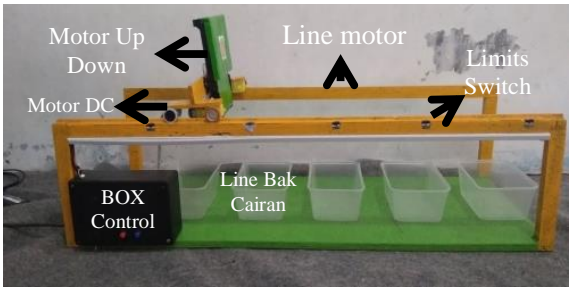

Gambar 3.1 Alat Konveyor Auto Electroplating Berbasis Arduino Mega

\subsubsection{Perancangan Program Arduino dengan Software Arduino IDE}

Perancangan program pada Arduino menggunakan software Arduino IDE untuk mempermudah pembuatan program pada Arduino. Banyak perintah yang digunakan dalam pembuatan program untuk alat tugas akhir ini. Berikut akan dicantumkan beberapa perintah yang digunakan. Untuk lebih jelasnya sketch program terlampir pada laporan tugas akhir ini.

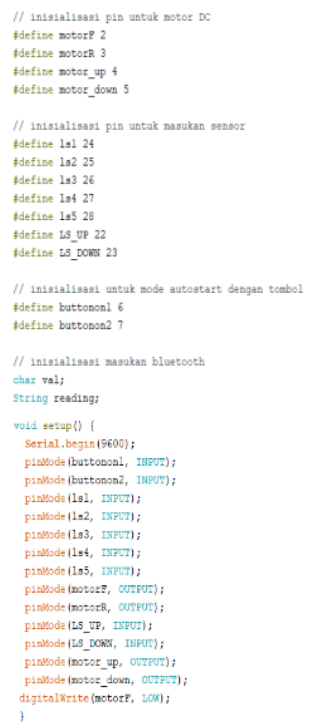

Gambar 4.2 Sebagian sketch program Arduino

\subsubsection{Perancangan Software untuk Pengendali Via} Smartphone

\section{Perancangan Aplikasi}

Design yang dibuat dengan software APP Inventor mempermudah pembuatan aplikasi untuk pengoprasian alat yang dibuat. Pertama, install terlebih dahulu aplikasinya, dapat didownload melalui link : http://bit.ly/AplikasiTAbaqusari. Lalu aktifkan perangkat Bluetooth sebagai pendukung pada smartphone. Adapun tampilannya sebagai berikut :

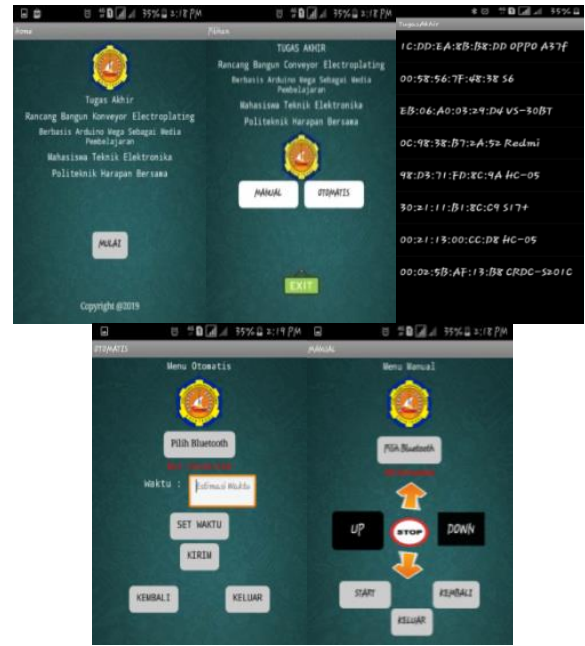

Gambar 4.3 Tampilan Aplikasi

\subsection{Cara Kerja Alat}

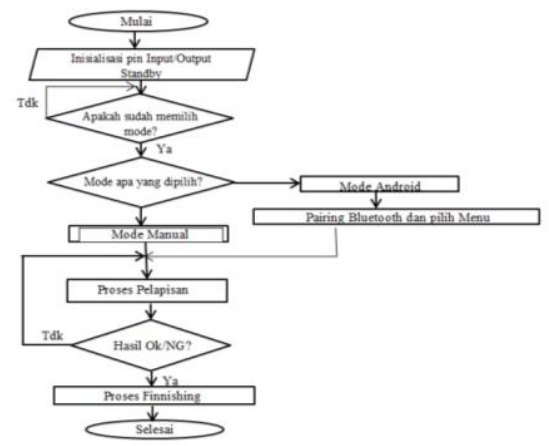

Gambar 4.4 Flowchart Alur Kinerja Alat

Ketika program dimulai maka akan masuk ke mode standby yang telah di setting dan akan melakukan eksekusi program awal. Apabila akan dilakukan mode otomatis, maka dapat menekan tombol yang telah disediakan dibox. Apabila ingin menjalankan dengan mode remote dapat dilakukan dengan pairing Bluetooth pada handphone dan dapat melalukan perintah motoran maju, mundur, naik dan turun secara manual.

\subsection{Pengoprasian Alat}

Ada 2 pengujian yang dilakukan terhadap alat konveyor auto electroplating. Pertama pengujian terhadap pergerakan motoran yang dihasilkan melalui tombol manual pada box dan yang ke dua adalah penggunaan kontrol manual menggunakan smarthpone android.

4.3.1. Pengujian Konveyor Auto Electroplating dengan 


\section{Tombol Autostart}

Dalam satu alat yang dibuat, terdapat 7 sensor utama yang akan aktif apabila tertekan oleh ban motor dc, 5 sensor untuk menentukan motor dc berhenti dan 2 lagi untuk memerintahkan motor dc yang lain untuk proses pencelupan. Tabel 4.1 Hasil uji dengan tombol Autostart

\begin{tabular}{|c|c|c|c|c|c|}
\hline No & $\begin{array}{c}\text { Senso } \\
\mathrm{r}\end{array}$ & Cairan & Timer & $\begin{array}{c}\text { Hasil } \\
\text { Uji }\end{array}$ & Keterangan \\
\hline 1 & LS 1 & 1 (Bilas) & 30 detik & OK & Dapat diperoses \\
\hline 2 & LS 2 & 2 (Kimia 1) & 60 detik & OK & Dapat diperoses \\
\hline 3 & LS 3 & 3 (Bilas) & 30 detik & OK & Dapat diperoses \\
\hline 4 & LS 4 & 4 (Kimia 2) & 60 detik & OK & Dapat diperoses \\
\hline 5 & LS 5 & 5 (Bilas) & 30 detik & OK & Dapat diperoses \\
\hline 6 & LS 6 & 2 detik & OK & $\begin{array}{c}\text { Dapat diperoses / } \\
\text { untuk non- } \\
\text { aktifkan motor } \\
\text { DC saat } \\
\text { mengangkat plat }\end{array}$ \\
\hline 7 & LS 7 & 2 detik & OK & $\begin{array}{c}\text { Dapat diperoses / } \\
\text { untuk non- } \\
\text { aktifkan motor } \\
\text { DC saat } \\
\text { Mencelupkan plat }\end{array}$ \\
\hline
\end{tabular}

Penjelasan maksud dari tabel diatas yaitu :

a. Saat perangkat mulai diposisi On/Standby belum ada input masuk maka perangkat akan dalam posisi standby/tidak melakukan kegiatan

b. Saat tombol autostart pada papan panel ditekan maka akan mengirimkan sinyal kepada arduino dan diolah kemabl oleh Driver L289N sehingga mengaktifkan motorrun yang membawa motorupdown untuk bergerak maju.

c. Saat LS1 tertekan oleh ban motorrun akan mengirimkan sinyal kepada arduino dan diolah kembali oleh Driver L289N sehingga menon-aktifkan motorrun disaat yang bersamaan motorupdown akan turun dengan membawa plat/bahan kerja yang telah digantung didudukan motorupdown.

d. Saat proses pencelupan awal/LS1 selesai dengan waktu yang telah ditentukan secara otomatis motorupdown akan mengangkat plat/bahan kerja yang telah digantung didudukan motorupdown dan saat LS6 tertekan oleh dudukan motorupdown bagian atas maka motorupdown akan berlogika LOW, lalu motorrun akan aktif kembali.

e. Proses tersebut akan berulang hingga pada cairan terakhir atau LS 5. Pada saat proses pencelupan diakhir maka conveyor diprogram langsung kembali ke posisi awal dan berhenti

\subsubsection{Pengujian Range Kontrol Manual/Auto dengan} Android

Tabel 4.2 Pengujian range kontrol manual nirkabel

\begin{tabular}{|c|c|c|l|}
\hline No & $\begin{array}{c}\text { Jarak } \\
\text { Uji }\end{array}$ & Hasil Uji & Keterangan \\
\hline 1. & $2 \mathrm{~m}$ & OK & Dapat Diproses \\
\hline 2. & $4 \mathrm{~m}$ & OK & Dapat Diproses \\
\hline 3. & $6 \mathrm{~m}$ & OK & Dapat Diproses \\
\hline 4. & $8 \mathrm{~m}$ & OK & Dapat Diproses \\
\hline 5. & $10 \mathrm{~m}$ & Sedang & Dapat Diproses \\
\hline 6. & $12 \mathrm{~m}$ & Sedang & Dapat Diproses \\
\hline 7. & $15 \mathrm{~m}$ & Sedang & Dapat Diproses (delay) \\
\hline 8. & $20 \mathrm{~m}$ & Sedang & Dapat Diproses (delay) \\
\hline 9. & $25 \mathrm{~m}$ & Buruk & Tidak dapat diproses \\
\hline
\end{tabular}

Jarak kontrol manual maksimal tergantung jarak anatara Arduino Mega dengan handphone, jika jarak Arduino Mega dan handphone pada jarak maksimal, maka proses pengiriman perintah dari handphone ke Arduino akan mengalami delay.

\section{Kesimpulan}

Dari uraian perancangan, implementasi dan pengujian mengenai pembutan Konveyor Auto Electroplating Berbasis Arduino
Mega, maka dapat diambil kesimpulan dan saran bahwa desain alat ini telah berhasil dibuat dan berfungsi dengan baik. Adapun alat ini terdiri dari beberapa bagian yaitu:

1. Modul konveyor ini dikontrol dengan Arduino Mega dengan bantuan dari Driver L298N untuk menggerakan motor DC.

2. Pengaplikasian App Inventor dapat digunakan untuk pengoprasian peralatan industry.

3. Jarak pada pengontrolan on/off secara manual melalui handphone melalui Bluetooth HC-05 hanya mencapai 20m, tidak lebih dari $20 \mathrm{~m}$.

4. Pengontrolan dengan secara manual dengan tombol pada panel lebih tepat dan apabila pengontrolan manual melalui smartphone berpotensi delay karena tergantung medan dan jarak antar pengontrol (remote) dengan penempatan alat.

5. Untuk memperluas jarak kontrol manual dengan smartphone, perlu dikembangkan lagi dengan perangkat yang dapat menjangkau jarak jauh.

\section{Daftar Pustaka}

[1]. [1] Nur'aningsih, Dyah. 2010. "Sistem Kendali Conveyor Otomatis Berbasis Mikrokontroller AT89S51”. Jurnal Ilmiah Teknologi \& Rekayasa. 15(3), 202-215

[2]. Nugroho, Fajar E, 2017, Tekad Tegal Kembali Menjadi Jepangnya Indonesia:

Liputan6.[Online].Tersedia https://www.liputan6.com/regional/read/2884873/tekad-tegalkembali-menjadi-jepangnya-indonesia. Diakses pada [28 Desember 2018]

[3]. Ir Azhar, A. Saleh. 2014. "Electroplating Teknik Pelapisan Logam dengan Cara Listrik". Yrama Widya. Bandung

[4]. Djuandi, Fery. 2011. "Pengenalan Arduino". Jakarta: Elexmedia

[5]. Dian, Artanto. 2012."Interaksi Arduino dan labVIEW" Elexmedia. Jakarta: Elexmedia

[6]. Kadir, Abdul. 2015. "From Zero to A Pro Arduino". Yogyakarta: ANDI.

[7]. Arsyad. 2002. "Media Pembelajaran". Jakarta: Rajawali Pres

[8]. Sudjana. 2002. "Metode Statistika. Edisi keenam.”. Bandung: Tarsito.

[9]. Admin, 2015. Sekilas Profil D3 Teknik Elektronika:Polteknik Tegal.[Online].Tersedia http://poltektegal.ac.id/v2012/?page id=139. Diakses Pada [28 Desember 2018]

[10]. Sugiyono. 2006. "Metode Penelitian Kuantitatif Kualitatif dan $R \& D ”$. Bandung: Alfabeta. 